\title{
LEPROSY IN BALI, INDONESIA
}

\author{
by Dr. N. D. Frasier, M.B., Ch.B., D.T.M.\& H. \\ Medical Secretary, The Mission to Lepers
}

The following information is abstracted from reports sent to The Mission to Lepers by Dr. E. SPEnCER ReEld, Government Leprosy Officer, Den Pasar, Bali, Indonesia.

Bali is a diamond-shaped island, about 85 miles by 55 miles, lying at the Eastern tip of Java, with a population of about 2,000,000 people. The religion is predominantly Balinese Hindu and this permeates to the very core of the lives of the people in the villages.

\section{Government Leprosaria}

There are six leprosaria sited around the island. The number of in-patients in December 1959 was 292; in December 1960 it was 277. Most of these patients have gross deformities and mutilations. The accommodation provided is rough and simple, but generous rations keep the patients remarkably happy.

Medical supervision is carried out by the Leprosy Officer once a month, by an assistant once a week, and by a "dresser" daily.

These leprosaria are mainly social homes for the aged, the destitute and the maimed, and for orphans. They do not come within the planning of leprosy eradication.

\section{Clinical Unit}

A Clinical Unit was completed at Den Pasar in 1959, and is the organizing centre for the anti-leprosy campaign. It provides 28 beds for the admission of patients from the out-patient clinics, who are needing treatment for complications or for intercurrent infections. It provides accommodation for the treatment of out-patients; 12 rooms for patients employed to assist with the work; offices, dispensary and laboratory, and store rooms.

In the first ten months following the opening of the ward unit 50 patients were admitted, and 28 were still under treatment at the time the report was written. The conditions for which the patients were admitted were as follows:

1. For reaction conditions $\quad \ldots \quad \ldots \quad 29$ patients

2. For grossly infected ulcers $\ldots \quad \ldots \quad 7$ patients

3. For malnutrition and neglect $\quad \ldots \quad 3$ patients

4. For acute infections ... $\quad \ldots \quad \ldots \quad$... 9 patients

5. For spiritual rehabilitation $\ldots \quad \ldots \quad \ldots \quad 1$ patient

6. For operation for ectropion $\quad \ldots \quad 1$ patient 


\section{Treatment places}

Arrangements have been made to give treatments at some 95 places, including 34 general hospitals and polyclinics, 26 shelters of bamboo and coconut (mostly provided by the villages and erected by the patients themselves), 20 under roadside trees, or in the houses of patients, 6 in connection with the Government leprosaria, and 1 at the special clinical unit.

Dr. Reed writes, "Headway at last seems to have been made in the last area in Bali where there is not only a high incidence of leprosy, but also a strong resistance to any efforts to provide places for treatment. Now two locally elected officials have proved most helpful, and something will almost certainly be done in the near future. This will mean that our first objective has been attainedthe provision of places at which patients can get treatment within reasonable walking distance (up to 3-4 miles) of their homes".

\section{Workers}

The finding, employment and training of suitable men to assist with this programme has provided Dr. Reed with many problems, and inherent difficulties have been greatly increased by rising prices and widespread economic disturbances. Trained and untrained workers have been employed, and on the whole the untrained workers have proved the more satisfactory for "nearly all have now caught the spirit of the campaign which is so important in winning the confidence of the patients and ensuring regularity in their attendance; they are now giving out the DDS tablets conscientiously, and, mostly, accurately".

"But the brightest side of the picture is the willing help given by some of the more intelligent patients of the younger generation, most of whom have now been to school for a period. One of these is the only reliable person available to do such administrative work as the accurate keeping of the central register. These patients are invaluable also in encouraging new ones to attend regularly, as they will take the trouble to explain patiently just what is involved".

\section{Transport}

All available forms of transport are used by those attending to the patients in the clinics. The Government has provided a jeep and two motor cycles which are used to visit the more distant places in the mountains. Other workers use motorised bicycles, a number of which were supplied by UNICEF and by The Mission to Lepers. Yet others use the buses or the local hospital jeep. Petrol and maintenance is met by Government grants with some assistance from The Mission to Lepers. 
Two new areas were opened up during 1960, one of them being a small island 20 miles off the coast and reached only by outrigger canoe. "This island is mountainous without any roads so visiting means a 60-mile trek, with only bare boards as a bed at night, and plain rice without meat or vegetables for meals". However in three special tours undertaken either by the doctor or the male nurse 75 new patients were found.

\section{Attendance}

The number of patients who were being treated at the end of December 1960 was 2,141. This includes both the 298 who were living in the government leprosaria, and 1,843 attending the clinics.

Those attending the clinics are classified as follows:

\begin{tabular}{lcccr} 
& Lepromatous & Tuberculoid & Indeterminate & Total \\
Male & 382 & 806 & 14 & 1,202 \\
Female & 154 & 482 & 5 & 641 \\
\hline
\end{tabular}

The number of voluntary new patients brought under treatment since the campaign started in Sept. 1956 is 1,658 Adding the number registered in Sept. $1956 \quad \ldots \quad \ldots \quad \ldots \quad 1,074$

the total is $\quad \ldots \quad 2,732$

\section{Treatment}

In the majority of cases DDS has been found the treatment of choice. Induction is begun for all patients with $25 \mathrm{mg}$. twice weekly for the first month. This is increased to $50 \mathrm{mg}$. for the second month, then to $100 \mathrm{mg}$. and in the $4 \mathrm{th}$ month two $100 \mathrm{mg}$. tablets are given on two days in each week.

Supplies of Ciba-1906 were also made available and were found of great value in the treatment of patients with tuberculoid reaction conditions. On the other hand 16 out of 18 cases admitted to the ward for persistent minor lepra and/or ENL episodes show as much intolerance to this drug as to DDS. All these cases are now on a lengthy course of desensitization by intramuscular injections of $50 \%$ Sulphetrone solution twice weekly, a method found most successful in earlier years before the ward was opened for the six reaction cases that lived within walking distance of the clinic. $100 \%$ of these patients have now tolerated full doses of DDS for over a year without any discomfort. 


\section{Progress}

Some indication of the progress that has been made is shown by the fact that "in one area where treatment has been given longest, and where there is no prejudice against new patients coming forward for treatment, there were 250 cases of "arrest" last year, while new patients totalled 100".

$29 \%$ of these new patients however already had developed some degree of minor disability when they presented themselves. Many of these conditions would respond to reatment.

Severe mutilations were present in only $3 \%$ of the new patients, and this figure compares very favourably with that of $28 \%$ of the total in 1956.

Certificates of arrest have so far been issued to 376 patients.

\section{Propaganda and Public Opinion}

Dr. Reed reports "Almost a medico-social revolution has taken place in the attitude of the community towards patients and their illness mainly owing to the remarkable effect of DDS in preventing hideous deformities, which surely are the main cause of the worldwide fear of the illness. This means that it is now rare for a patient to be hounded out of his occupation. Even those with pre-treatment deformities have learnt to compensate for these in a remarkable way so that to all intents and purposes all our out-patients are employable, and all but a very few lazy ones do in fact perform traditional family and community duties.

In fact, recently a new problem has arisen. Attendances in a widespread area suddenly fell, the reason being that the patients had been included in the village work list for communal rice gathering. One of these villages was fanatical in its attitude to the illness only a few years ago.

The very fact that patients are getting better before their eyes is perhaps the most important reason for the changing attitude; but a tape recorder has also been used to give talks in Balinese in villages where prejudice has been most marked. 10,000 information leaflets have also been distributed.

\section{Home Visits}

Arrangements made for visiting the homes of patients have not been carried out as conscientiously as is desired. Such visits are needed to find out the reason for failure to attend regularly at the clinics; and to make yearly examinations of contacts of lepromatous patients.

\section{WHO Survey}

During 1960 Dr. Reed helped organise a WHO "Pilot Project" 
in return for which he was provided with free supplies of DDS and the use of a station wagon. Three erstwhile yaws campaign workers were specially trained to detect the early signs of leprosy. In the course of the year 73,000 persons were examined, amongst whom 24 new leprosy cases were found.

Dr. Reed's conclusions confirm those of other experienced leprosy workers that the most practical and economical way to get new patients is to establish treatment centres in those areas where leprosy is known to exist. Within one or two years the good results of treatment are sufficiently self-advertising to draw in voluntarily an increasing number of shy and as yet unknown patients. Contact tracing of these patients by a good conscientious worker can then lead to excellent results.

Supplies of Sulphetrone from B. W. \& Co., of Ciba 1906 from Ciba, of Etisul from I.C.I. are gratefully acknowledged, as well as the support of the Head of the Bali Health Department, of UNICEF and of The Mission to Lepers. 